\title{
A Micro Polymerase Chain Reaction Module for Integrated and Portable DNA Analysis Systems
}

\author{
Elisa Morganti, ${ }^{1}$ Cristian Collini, ${ }^{1}$ Cristina Potrich, ${ }^{1}$ Cristina Ress, ${ }^{1,2}$ Andrea Adami, ${ }^{1}$ \\ Leandro Lorenzelli, ${ }^{1}$ and Cecilia Pederzolli ${ }^{1}$ \\ ${ }^{1}$ FBK-Center for Materials and Microsystems, 38100 Trento, Italy \\ ${ }^{2}$ Department of Information Engineering and Computer Science, University of Trento, 38123 Trento, Italy
}

Correspondence should be addressed to Elisa Morganti, morganti@fbk.eu and

Leandro Lorenzelli, lorenzel@fbk.eu

Received 31 August 2010; Revised 12 November 2010; Accepted 20 January 2011

Academic Editor: P. Siciliano

Copyright (C) 2011 Elisa Morganti et al. This is an open access article distributed under the Creative Commons Attribution License, which permits unrestricted use, distribution, and reproduction in any medium, provided the original work is properly cited.

\begin{abstract}
This work deals with the design, fabrication, and thermal characterization of a disposable miniaturized Polymerase Chain Reaction (PCR) module that will be integrated in a portable and fast DNA analysis system. It is composed of two independent parts: a silicon substrate with embedded heater and thermometers and a PDMS (PolyDiMethylSiloxane) chamber reactor as disposable element; the contact between the two parts is assured by a mechanical clamping obtained using a Plastic Leaded Chip Carrier (PLCC). This PLCC is also useful, avoid the PCR mix evaporation during the thermal cycles. Finite Element Analysis was used to evaluate the thermal requirements of the device. The thermal behaviour of the device was characterized revealing that the temperature can be controlled with a precision of $\pm 0.5^{\circ} \mathrm{C}$. Different concentrations of carbon nanopowder were mixed to the PDMS curing agent in order to increase the PDMS thermal conductivity and so the temperature control accuracy.
\end{abstract}

\section{Introduction}

This work shows the design, fabrication, and thermal characterization of a $\mu$ PCR module to be inserted in a primary care diagnostic Lab-On-Chip platform for genetic analysis. In the final LOC device, the designed $\mu \mathrm{PCR}$ module will be integrated with a label-free detector of DNA hybridization based on piezoresistive cantilever. A fluidic network based on pneumatic valves and pumps will provide the required fluidic handling and connections (Figure 1). The two modules will be mounted on a custom made PCB board and all the microfluidics will be integrated in the same PDMS layer connecting the devices.

Since the 1990s, PCR micro devices have undergone widespread and rapid development. Chamber PCR [1-3] and continuous flow PCR (CFPCR) $[4,5]$ have been the mainly investigated configurations over the last years. While the first configuration uses a static approach, the second configuration can be considered as a dynamic system because it is characterized by a continuous flow of the reaction mixture through different thermostatic zones. Moreover, in the last few years, other original PCR chipshave been developed [6-8] and different materials such, as silicon-glass [9], Polydimethylsiloxane (PDMS) [9-11], SU-8 [12], polymethylmethacrylate (PMMA) [13], and polycarbonate (PC) [14] have been studied as well. Considering the benefitsand drawbacks of the two mostly diffused PCR configurations, this work is focused on the development of a micro chamber since it does not require complex microfluidics in the prospective of an easier fluidic handling for the final integrated system. In its first realization, the PCR device is composed of two different parts: a silicon fixed part for temperature control and a cheap disposable PDMS chamber for single use applications such as DNA amplification.

\section{Materials and Methods}

2.1. Microdevice Design and Fabrication Process. The amplification device consists of a microchamber reactor in which the PCR mix is confined and subjected to the thermal cycling. The chamber is completely made of PDMS placed on the top of a silicon substrate, in order to exploit the silicon 


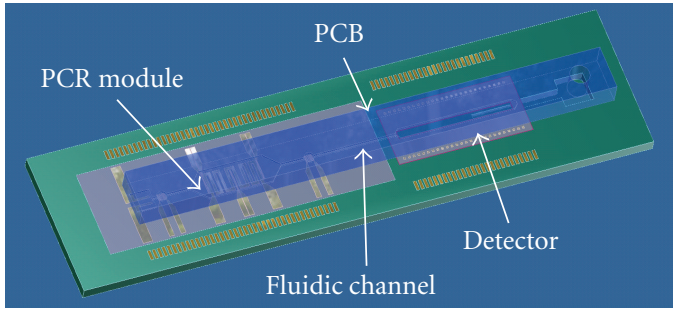

Figure 1: Sketch of the final lab-on-chip with PCR module, cantilever-based detector and fluidic channels.

thermal characteristics and make the thermal cycle faster. The temperature control system is implemented by means of platinum micro heaters and thermometers realized on the silicon. PDMS was chosen as building material because it is biocompatible, transparent, and easily moldable.

The reaction chamber has a polygonal shape in order to facilitate the liquid movement and to avoid residual at the edges. The chamber is $7 \mathrm{~mm}$ long, $3 \mathrm{~mm}$ wide, and $210 \mu \mathrm{m}$ deep with a total volume of $4.4 \mu \mathrm{L}$. Considering the inlet and outlet channels, the volume rises up to $6.5 \mu \mathrm{L}$. The platinum heater has a serpentine shape larger in the middle in order to make a uniform heat generation. The heater resistance is $165 \Omega$, while the thermometers have a resistance of $680 \Omega$ at room temperature. The measured TCR for the thermometer is $2540 \mathrm{ppm} /{ }^{\circ} \mathrm{C}$. The total dimensions of the PCR device are $9 \mathrm{~mm} \times 4 \mathrm{~mm} \times 3 \mathrm{~mm}$.

The fabrication process is divided in two separated steps: the chamber was realized using soft-lithography techniques, while the silicon membrane and the heater were micromachined in conventional MEMS technologies.

For this second part, the process started with a 4-inch silicon wafer covered with a multilayer of dielectric for a good insulation (300 nm of Growth Silicon Dioxide, $100 \mathrm{~nm}$ of LPCVD, $300 \mathrm{~nm}$ of TEOS). Negative photoresist was then spun on the wafer and patterned using photolithography technique in order to define the heater and thermometer for the following lift-off step (Figure 2(a)). The wafer was inserted in e-gun evaporator (ULVAC EBX-16C) and a layer of chromium/platinum $(5 / 150 \mathrm{~nm})$ was evaporated on the surface. The unexposed photoresist was removed using acetone in ultrasonic bath and the $\mathrm{Cr} / \mathrm{Pt}$ was sintered at $500^{\circ} \mathrm{C}$ for 1 hour. Finally $400 \mathrm{~nm}$ of $\mathrm{PECVD} \mathrm{SiO}_{2}$ was deposited on the wafer in order to passivate the heaters and thermometers and to provide a bonding layer for the PDMS. A $90 \mu \mathrm{m}$ silicon membrane was also obtained using TMAH wet etching.

For what concerns the PDMS chamber, a master of the reactor was obtained by spinning and patterning a thick layer of SU-8 on a silicon substrate (Figure 2(b)). PDMS, in ratio of $5: 1$ ( $5 \mathrm{~g}$ of prepolymer and $1 \mathrm{~g}$ of curing agent), was then poured on the master, let polymerize for 20 minutes at $80^{\circ} \mathrm{C}$ and peeled away. Holes ( $1 \mathrm{~mm}$ in diameter) were punched to realize fluidic connections. In the meantime, a thin membrane $(400 \mu \mathrm{m})$ of PDMS $(20: 1)$ was obtained and prepolymerized 10 minutes at $80^{\circ} \mathrm{C}$. The two layers were placed one on top of the other and permanently glued after the complete polymerization of the PDMS. The silicon layer and the PDMS layer were then bonded together using mechanical clamp if reversible bonding is required or oxygen plasma bonding $\left(25 \mathrm{~s}, 80 \mathrm{~W}, 10 \mathrm{sccm} \mathrm{O}_{2}\right)$ using a commercial plasma cleaner (Diener FEMTO) for permanent bonding. In this experiment, mechanical temporary bonding was used. The PLCC provided a distributed pressure on the surface of the chip. In this way, the thermal contact between the PDMS chamber and the silicon substrate was guaranteed without breaking the thin membrane.

2.2. Analytical Simulations. The design of the device was supported by analytical and finite elements simulations in such a way to evaluate the thermal requirements (Figure 3 ). A coupled thermal electric simulation was performed using Ansys. Two different elements were used for the modeling: the thermo-electric element SOLID69 for the heater and the thermal element SOLID70 for the other components. The simulated structure is a stack of different materials: the PCB on the bottom, the silicon bulk with $90 \mu \mathrm{m}$ thick silicon membrane, the platinum heater and the PDMS chamber filled with the PCR mix. The material properties are reported in Table 1.

A voltage of $22 \mathrm{~V}(2.9 \mathrm{~W})$ was applied to the heater and a boundary condition of convection was applied to the external walls. Simulations show that in this condition, good temperature uniformity is achieved in the PCR chamber. The silicon surface reaches the $95^{\circ} \mathrm{C}$ from $65^{\circ} \mathrm{C}$ with a rate of $10^{\circ} \mathrm{C} / \mathrm{s}$ and cools down from $95^{\circ} \mathrm{C}$ to $65^{\circ} \mathrm{C}$ with a rate of $1.7^{\circ} \mathrm{C} / \mathrm{s}$.

As a negative aspect, simulation shows that with $400 \mu \mathrm{m}$ of PDMS membrane, the temperature in the chamber after 30 s simulation is $8^{\circ} \mathrm{C}$ lower than the temperature on the surface of the silicon due to the low thermal conductivity of the PDMS (see Figure 3). The conductivity of the PDMS membrane should be increased for a better temperature control.

2.3. Electronic Control. An electronic board was designed and realized to control the embedded heater. The control is based on PID controller coupled to a PWM to regulate the input power. The PID receives the actual temperature value from the internal thermometer in a feedback configuration, as sketched in Figure 4.

A microcontroller (ATMEL atmega16) was used to implement the PID, the PWM, and the ADCfor data visualization and storing. The electronic board communicates with a computer through a serial-USB interface (FTDI MM232) (Figure 5).

A LabView VI is used to pass to the microcontroller all the parameters for the PCR cycle (number of cycle, temperature, duration). This setup is able to control the temperature with a precision of $0.5^{\circ} \mathrm{C}$.

2.4. PCR and Gel Electrophoresis. PCR was performed in the PDMS chamber with a total volume of $6 \mu \mathrm{L}$ reaction mixture containing 1X PCR buffer (Roche), each 0.2 mMdeoxynucleotide triphosphates (dNTP) (Applied Biosystems), $0.5 \mathrm{mM}$ of forward and reverse primers, $30 \mathrm{ng}$ of purified human genomic DNA, and $1 \mathrm{U}$ of FastStartTaq 


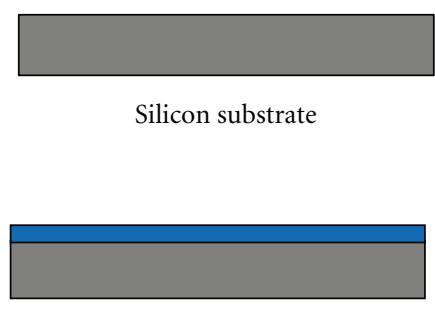

Negative photoresist deposition

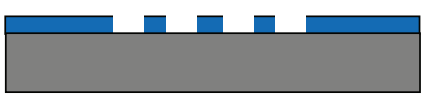

Photoresist patterning by lithographic techniques

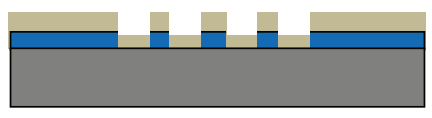

$\mathrm{Cr} / \mathrm{Pt}$ evaporation $(5 \mathrm{~nm} / 150 \mathrm{~nm})$

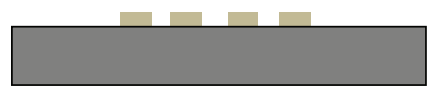

Heater definition using lift-off

(a)

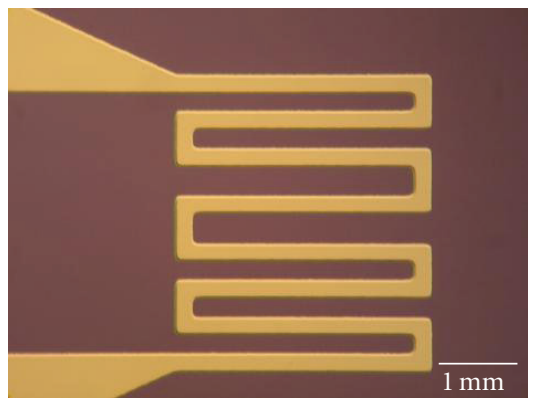

Fabricated microheater

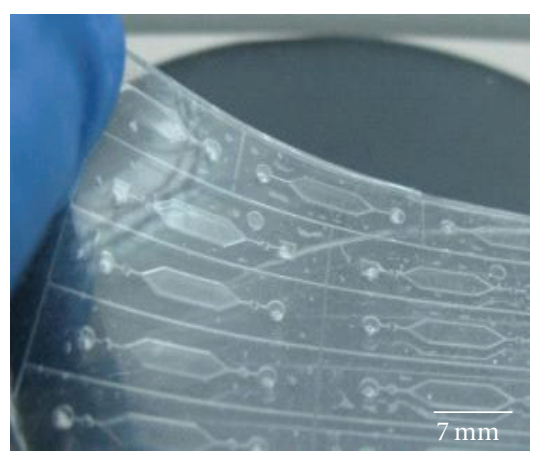

PDMS reaction chamber

(b)

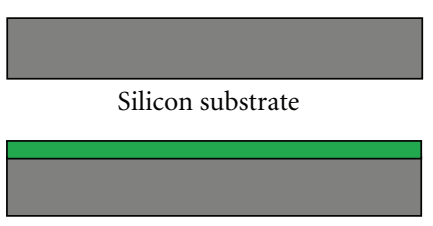

SU-8 3050 spinning three times @ 2000 rpm SU-8 thickness: $210 \mu \mathrm{m}$

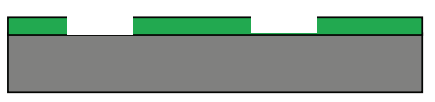

SU-8 patterning by UV-lithography

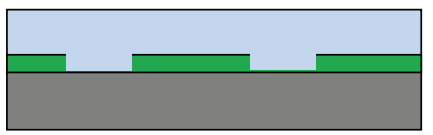

PDMS pouring

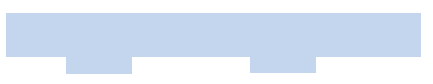

PDMS peeling and chamber release

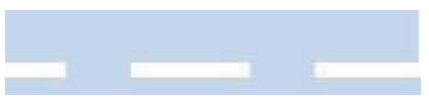

Chamber sealing with PDMS

(c)

FIgURE 2: Device fabrication process. (a) Fabrication of the silicon layer with heater and thermometers; (b) picture of the fabricated heater serpentine (top) and PDMS microchambers (bottom); (c) fabrication of the PDMS chambers.

TABLE 1: Material properties.

\begin{tabular}{lccc}
\hline Material & Resistivity $\Omega /$ square & Thermal conductivity $(\mathrm{W} / \mathrm{mK})$ & Heat capacitance $(\mathrm{J} / \mathrm{KgK})$ \\
\hline Platinum & 0.96 & 71.6 & 192 \\
PDMS & - & 0.15 & 1460 \\
Silicon & - & 150 & 700 \\
PCB & - & 0.2 & 2000 \\
\hline
\end{tabular}

DNA polymerase (Roche). The following primers related to the hemochromatosis gene were utilized: C282Yforward (TGGCAAGGGTAAACAGATCC) and C282Yreverse (TACCTCCTCAGGCACTCCTC). For the amplification, the following protocol was used: $10 \mathrm{~min}$ at $95^{\circ} \mathrm{C}$ for the initial denaturation step, $60 \mathrm{sec}$ at $95^{\circ} \mathrm{C}, 60 \mathrm{sec}$ at $62^{\circ} \mathrm{C}$, and $60 \mathrm{sec}$ at $72^{\circ} \mathrm{C}$ (these 3 steps were repeated for 35 cycles), and $7 \mathrm{~min}$ at $72^{\circ} \mathrm{C}$.

To check the presence of the PCR product, a gel electrophoresis was performed in TAE buffer $(40$ mMTrisAcetate and $1 \mathrm{mM}$ EDTA) by using 2\% agarose gel containing ehidium bromide $(0.125 \mathrm{mg} / \mathrm{mL})$ in a standard apparatus (BioRad).

\section{Results and Discussions}

3.1. Device Fabrication and Packaging. The described device was fabricated and bonded on PCB designed for a Plastic Leaded Chip Carrier (PLCC). The PLCC is used as a cap to prevent the evaporation of the PCR mix during the thermal cycle (Figure 6).

3.2. Thermal Characterization. The thermal characterization of the PCR chip was made at different levels. For comparison purposes we also used devices with bulk silicon without the etched membrane. Initially, the thermometer resistance was measured at room temperature and the resistance and 
Temperature contour plot

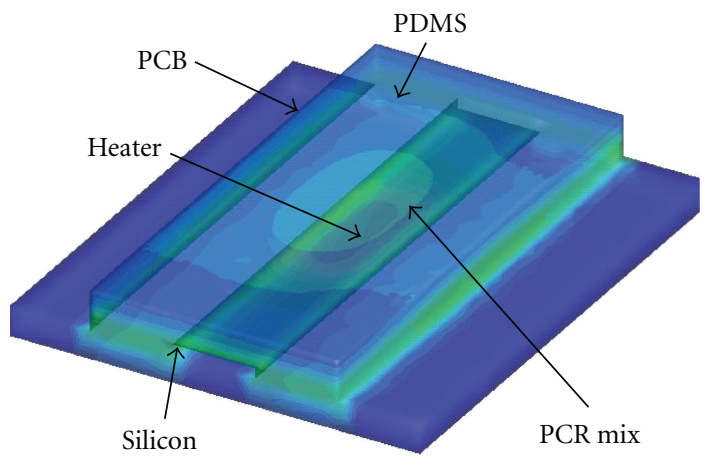

Temperature contour: section view

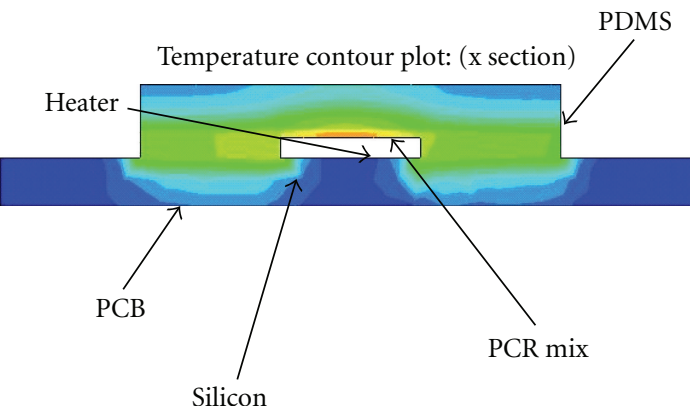

Temperature: $\begin{array}{lllllllllllllll}30 & 35 & 40 & 45 & 50 & 55 & 60 & 65 & 70 & 75 & 80 & 85 & 90 & 95\end{array}$

(a)

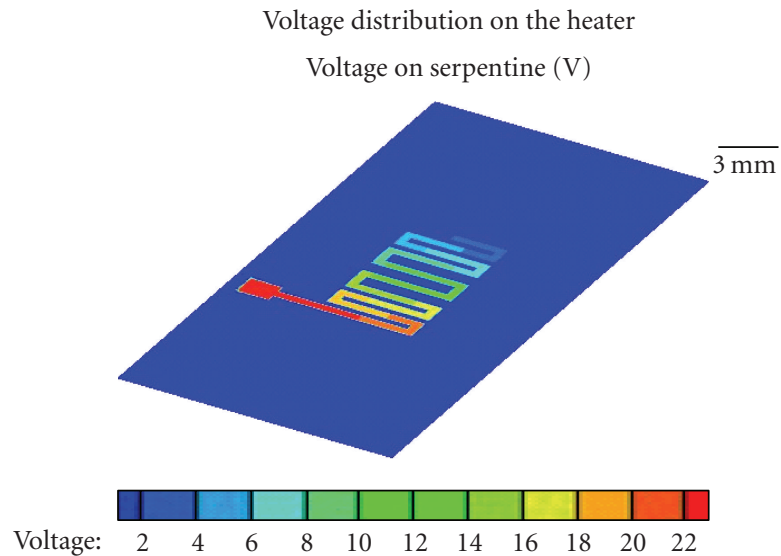

(b)

FIgURe 3: (a) Simulated temperature distribution in the PCR device; (b) simulated voltage distribution on the heater.

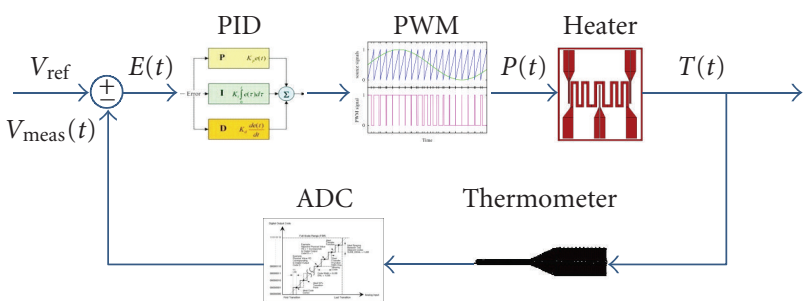

FIGURE 4: Schematic sketch of the temperature control loop.

temperature values were passed to the LabView VI for calibration. A voltage amplitude of $22 \mathrm{~V}(2.9 \mathrm{~W})$ was used for the thermal calibration. The program was started, and the value of the temperature read by the thermometer was plotted against the set point. In the case of bulk silicon device the results are reported in Figure 7.
As a second step, a thermocouple (Type $\mathrm{K}$ ) was used to test the reliability of the thermometer measurement. This test can be useful only in quasistatic configuration to validate the accuracy of the measured temperature; in fact, the thermal resistance of the thermocouple produces a delay in the answer (green curve) and so it can't be used in dynamic 


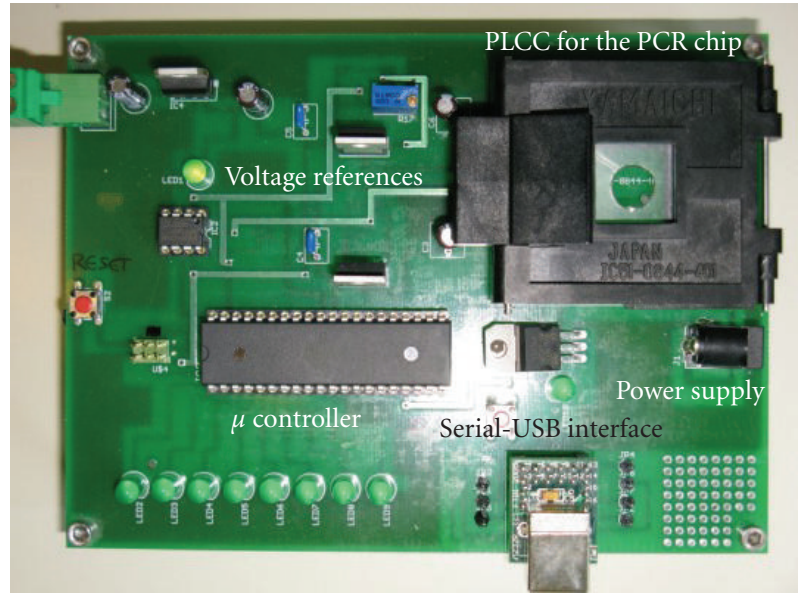

Figure 5: Picture of the realized electronic board. Total board dimensions are $15 \mathrm{~cm} \times 11 \mathrm{~cm}$.

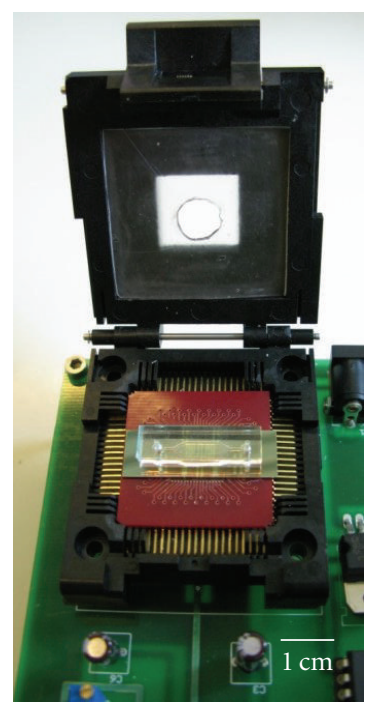

FIgURE 6: Picture of the fabricated device inserted in the PLCC.

measurements. As can be inferred from the graph, the system needs $23 \mathrm{~s}$ to cool from $95^{\circ} \mathrm{C}$ to $65^{\circ} \mathrm{C}\left(1.3^{\circ} \mathrm{C} / \mathrm{s}\right)$ and $12 \mathrm{~s}$ to reach up $95^{\circ} \mathrm{C}$ from $72^{\circ} \mathrm{C}$.

At this point, we tested the difference in cooling and heating time using three different devices: bulk silicon, long membrane and short membrane, configurations. The difference between the two kinds of membrane is that the long membrane is etched throughout the whole length of the chip thus creating a channel below the heater; instead, the short membrane is etched just below the heater forming a tub. As shown in Figure 8, with the long membrane the cooling time is about $15 \mathrm{~s}\left(2^{\circ} \mathrm{C} / \mathrm{s}\right)$ and the heating time from $72^{\circ} \mathrm{C}$ to $95^{\circ} \mathrm{C}$ is $1.5 \mathrm{~s}\left(11.5^{\circ} \mathrm{C} / \mathrm{s}\right)$.

For the preliminary thermal characterization tests, the PCR protocol includes an annealing step at $95^{\circ} \mathrm{C}$ for $5 \mathrm{~min}$

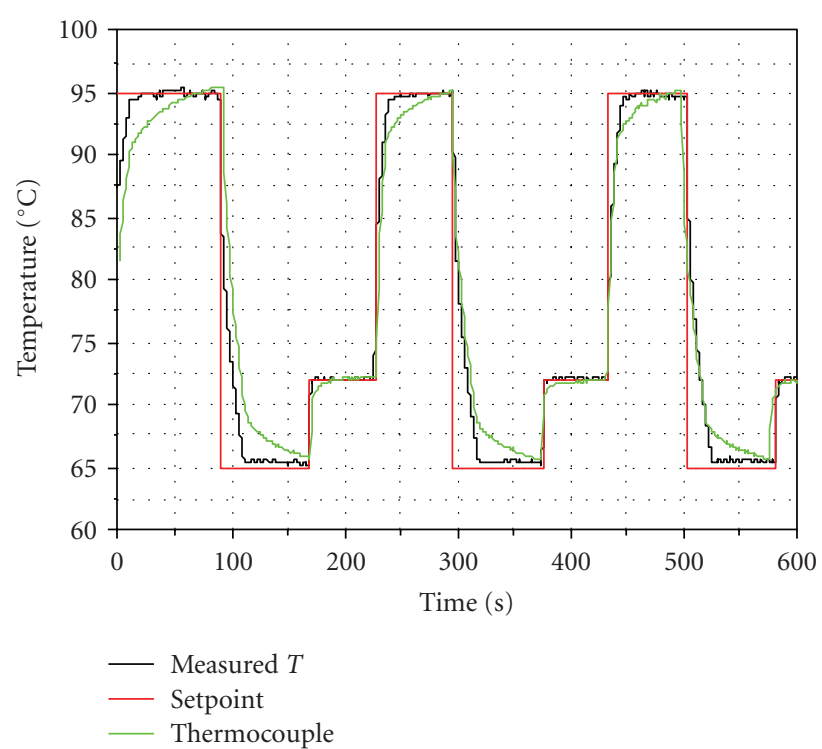

FIgURE 7: Temperature measured with internal thermometer (black) and thermocouple (green) versus set point (red).

followed by 35 cycle of denaturation $\left(95^{\circ} \mathrm{C}\right.$ for $\left.1 \mathrm{~min}\right)$, annealing $\left(65^{\circ} \mathrm{C}\right.$ for $\left.1 \mathrm{~min}\right)$, extension $\left(72^{\circ} \mathrm{C}\right.$ for $\left.1 \mathrm{~min}\right)$. At the end, the temperature is kept at $72^{\circ} \mathrm{C}$ for $7 \mathrm{~min}$. Considering the heating and cooling time, each cycle needs $105 \mathrm{~s}$ to be completed, so a whole PCR will take 2 hours.

If less power is required, using the long membrane configuration, half power is required to obtain the same heating time of the bulk silicon configuration $(16 \mathrm{~V}, 1.5 \mathrm{~W})$.

After the thermometer thermal characterization, we tried to characterize the PDMS membrane in the bottom of the PCR chamber. In this aim, we positioned the thermocouple just above a $400 \mu \mathrm{m}$ of PDMS. As expected from the simulation, the temperature after $30 \mathrm{~s}$ is lower than the set point as reported in Figure 9.

In order to improve PDMS thermal conductivity, we filled the polymer with carbon nanopowder. In particular, we mixed a certain quantity of carbon nanopowder with PDMS curing agent before adding the prepolymer in a ratio $20: 1$. Three different concentrations in weight of carbon powder versus curing agent were used: $1 \%$ carbon, $5 \%$ carbon, and $10 \%$ carbon. The measurements reported in Figure 11 show that in the case of $10 \%$ carbon, the temperature is much closer to the set point, thus increasing the temperature control accuracy.

The fabricated device was preliminarily tested using PCR mix for validating the effectiveness of the approach in the real conditions.

For the preliminary PCR test, the amplification of a DNA fragment related to the hemochromatosis disease was chosen. The thermal protocol (described in Section 2) was redundant from the biological point of view but it matched with the thermal characterization previously conducted (Figures 710). The positive result of the on chip PCR is shown in Figure 11, where a significant band due to the PCR product is clearly visible. 

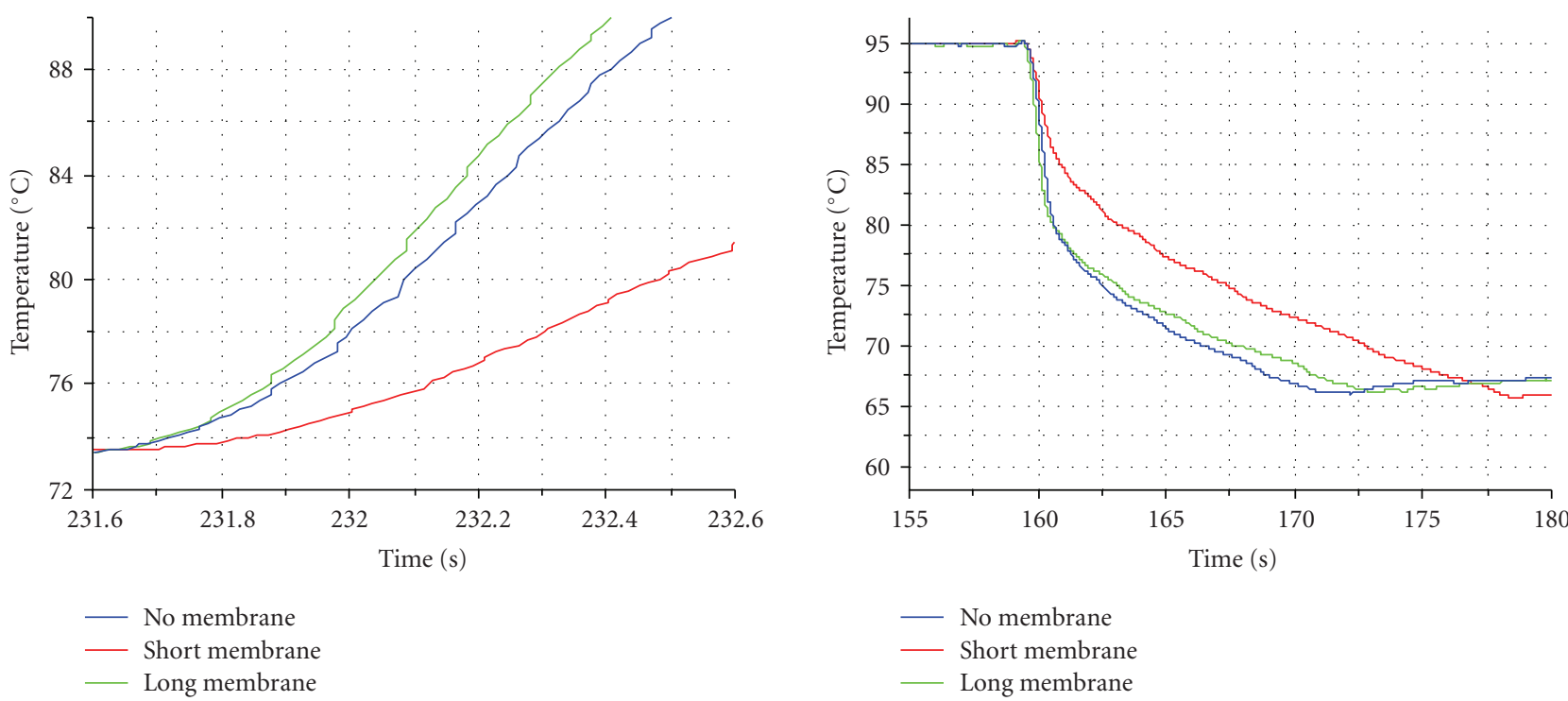

(a)

(b)

FIgURE 8: Heating (a) and cooling (b) of the silicon surface with different silicon membrane configurations: no membrane (red), short membrane (green), long membrane (blue).

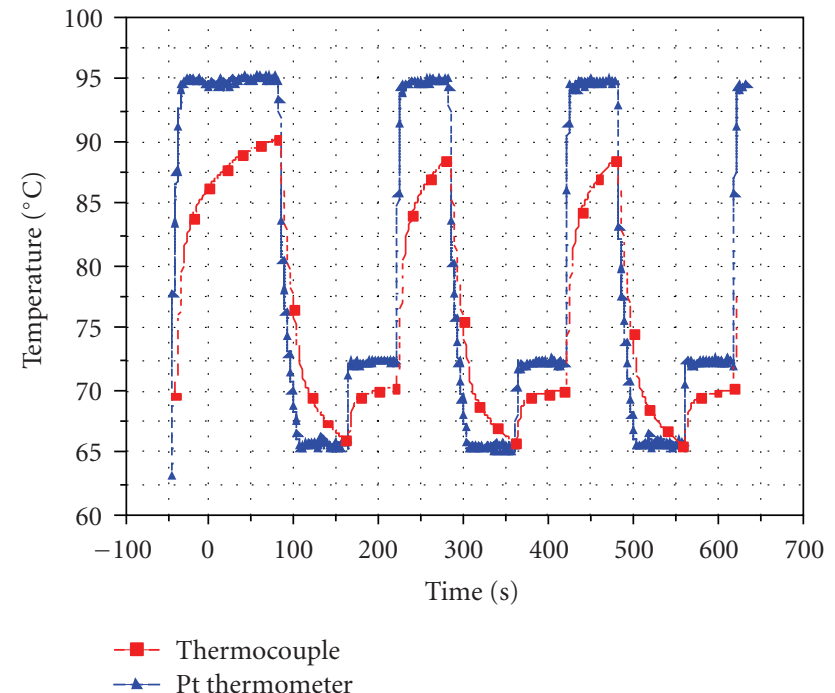

FIGURE 9: Measured temperature on the top of the PDMS membrane (blue) compared to the temperature read by the thermometer (red).

\section{Conclusions}

A chamber-type PCR module was realized and characterized in terms of thermal control. The use of carbon nanopowder has been demonstrated to optimize the heat exchange between the platinum on-chip heater and the reaction chamber. Analytical and FEM simulations have been used to

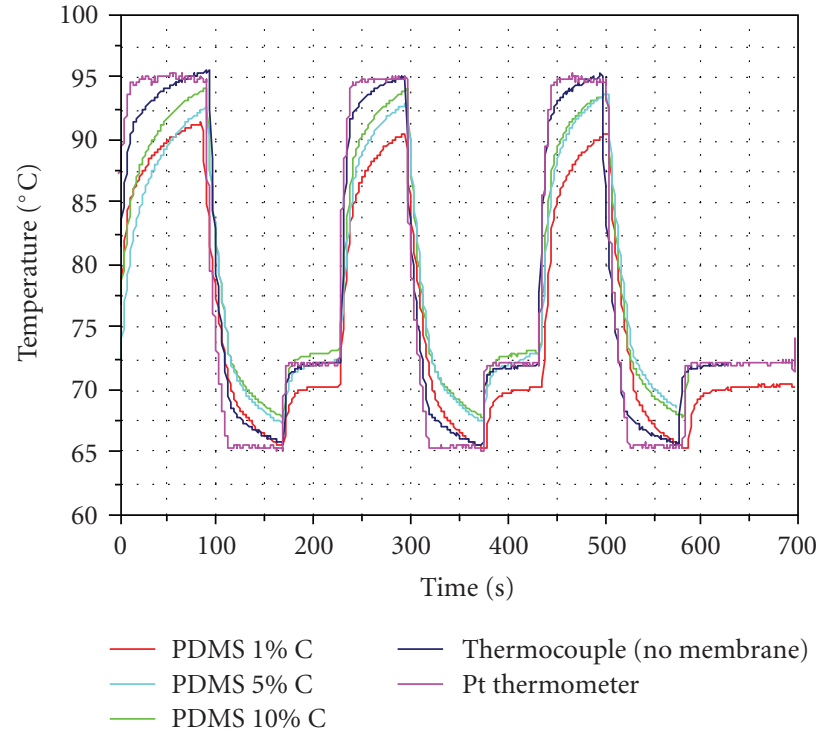

Figure 10: Comparison among the temperatures measured on the top of the PDMS membrane using different concentrations of the carbon nanopowder in the PDMS curing agent.

support the module design. PCR experiments in operative conditions have provided the validation of the approach. Currently, work is ongoing to integrate the detection and microfluidic modules in order to obtain the final integrated system. 


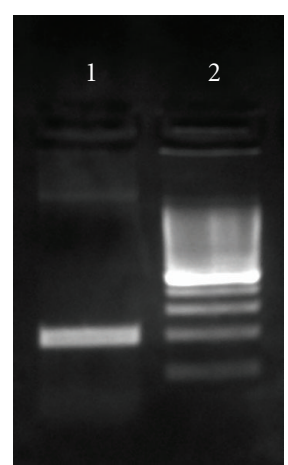

FIGURE 11: 2\% (a) garose gel electrophoresis of on chip PCR. (1) PCR product (400 bp); (2) $200 \mathrm{bp}$ ladder (Promega).

\section{Acknowledgments}

This work was possible thanks to the financial support of EU Project POCEMON (personal health systems for monitoring and point-of-care-Grant Agreement no. 216088) and thanks to the laboratory equipments provided by Fondazione Bruno Kessler. The authors want to thank Stefano Schmidt, Daniele Cortellazzi, and Andrea Tindiani for their help on the realization of the electronic board and the PDMS chambers.

\section{References}

[1] M. A. Northrup, M. T. Ching, R. M. White, and R. T. Watson, "DNA amplification in a micro fabricated reaction chamber," in Proceedings of the 7th International Conference on solid-state sensor and (Transducers '93), pp. 924-926, 1993.

[2] Z. Q. Zou, X. Chen, Q. H. Jin, M. S. Yang, and J. L. Zhao, "A novel miniaturized PCR multi-reactor array fabricated using flip-chip bonding techniques," Journal of Micromechanics and Microengineering, vol. 15, no. 8, pp. 1476-1481, 2005.

[3] M. U. Kopp, A. J. De Mello, and A. Manz, "Chemical amplification: continuous-flow PCR on a chip," Science, vol. 280, no. 5366, pp. 1046-1048, 1998.

[4] I. Schneegaß, R. Bräutigam, and J. M. Köhler, "Miniaturized flow-through PCR with different template types in a silicon chip thermocycler," Lab on a Chip, vol. 1, no. 1, pp. 42-49, 2001.

[5] M. Krishnan, V. M. Ugaz, and M. A. Burns, "PCR in a Rayleigh-Bénard convection cell," Science, vol. 298, no. 5594, pp. 298-793, 2002.

[6] Z. Guttenberg, H. Müller, H. Habermüller et al., "Planar chip device for PCR and hybridization with surface acoustic wave pump," Lab on a Chip, vol. 5, no. 3, pp. 308-317, 2005.

[7] E. A. Ottesen, W. H. Jong, S. R. Quake, and J. R. Leadbetter, "Microfluidic digital PCR enables multigene analysis of individual environmental bacteria," Science, vol. 314, no. 5804, pp. 1464-1467, 2006.

[8] I. Erill, S. Campoy, J. Barbè, and J. Aguilò, "Biochemical analysis and optimization of inhibition and absorption phenomena in glass-silicon PCR-chips," Sensor and Actuators B, vol. 96, pp. 685-692, 2003.

[9] A. R. Prakash, S. Adamia, V. Sieben, P. Pilarski, L. M. Pilarski, and C. J. Backhouse, "Small volume PCR in PDMS biochips with integrated fluid control and vapour barrier," Sensors and Actuators, B, vol. 113, no. 1, pp. 398-409, 2006.
[10] H. B. Liu, H. Q. Gong, N. Ramalingam, Y. Jiang, C. C. Dai, and K. M. Hui, "Micro air bubble formation and its control during polymerase chain reaction (PCR) in polydimethylsiloxane (PDMS) microreactors," Journal of Micromechanics and Microengineering, vol. 17, no. 10, pp. 2055-2064, 2007.

[11] N. B. Trung, M. Saito, H. Takabayashi, P. H. Viet, E. Tamiya, and Y. Takamura, "Multi-chamber PCR chip with simple liquid introduction utilizing the gas permeability of polydimethylsiloxane," Sensors and Actuators, B, vol. 149, pp. 284-290, 2010.

[12] T. B. Christensen, D. D. Bang, and A. Wolff, "Multiplex polymerase chain reaction (PCR) on a SU-8 chip," Microelectronic Engineering, vol. 85, no. 5-6, pp. 1278-1281, 2008.

[13] M. Hashimoto, F. Barany, and S. A. Soper, "Polymerase chain reaction/ligase detection reaction/hybridization assays using flow-through microfluidic devices for the detection of lowabundant DNA point mutations," Biosensors and Bioelectronics, vol. 21, no. 10, pp. 1915-1923, 2006.

[14] P. C. Chen, Accelerating micro-scale PCR (Polymerase Chain Reaction) for modular Lab-on-a-chip system, Ph.D. thesis, 2006. 

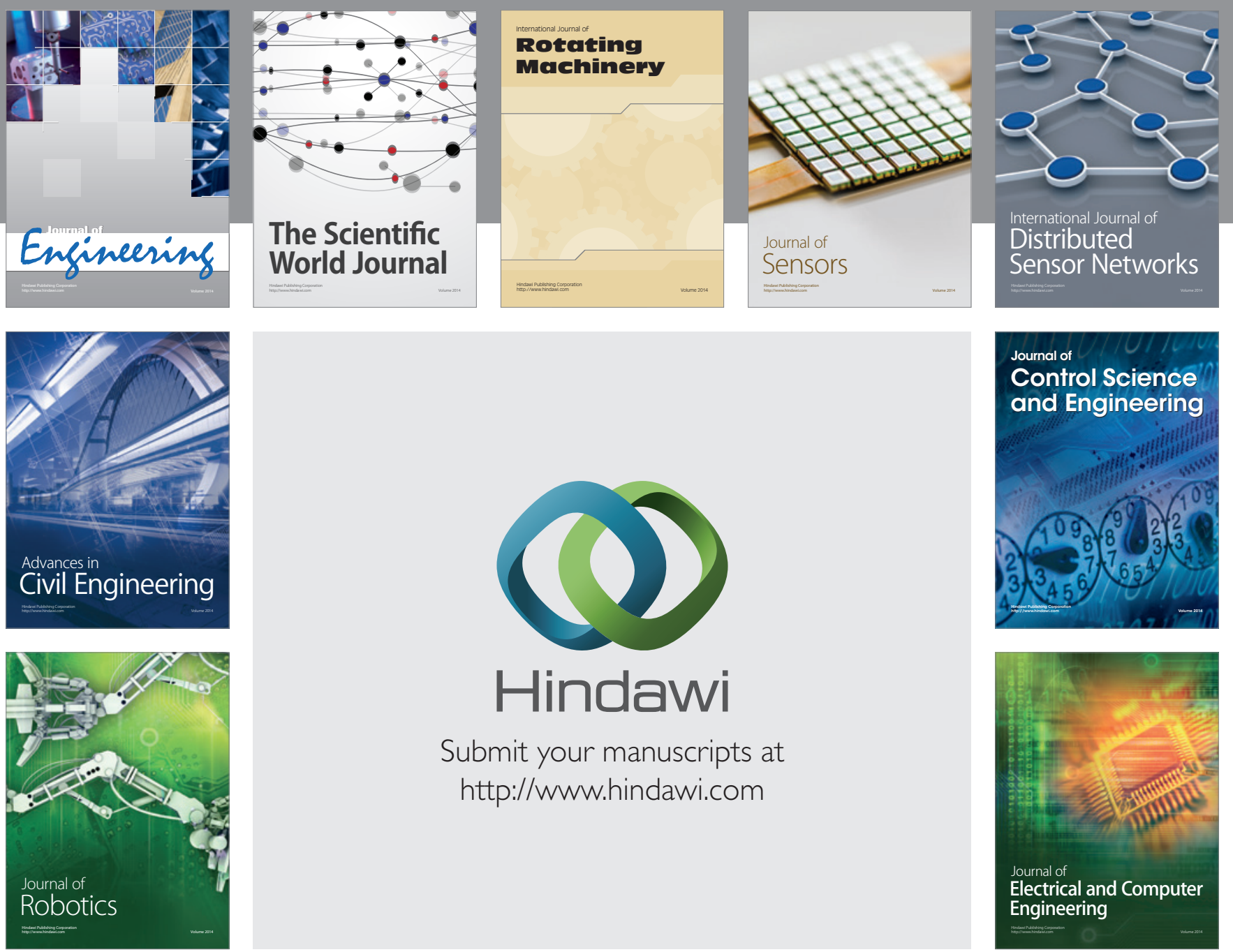

Submit your manuscripts at

http://www.hindawi.com
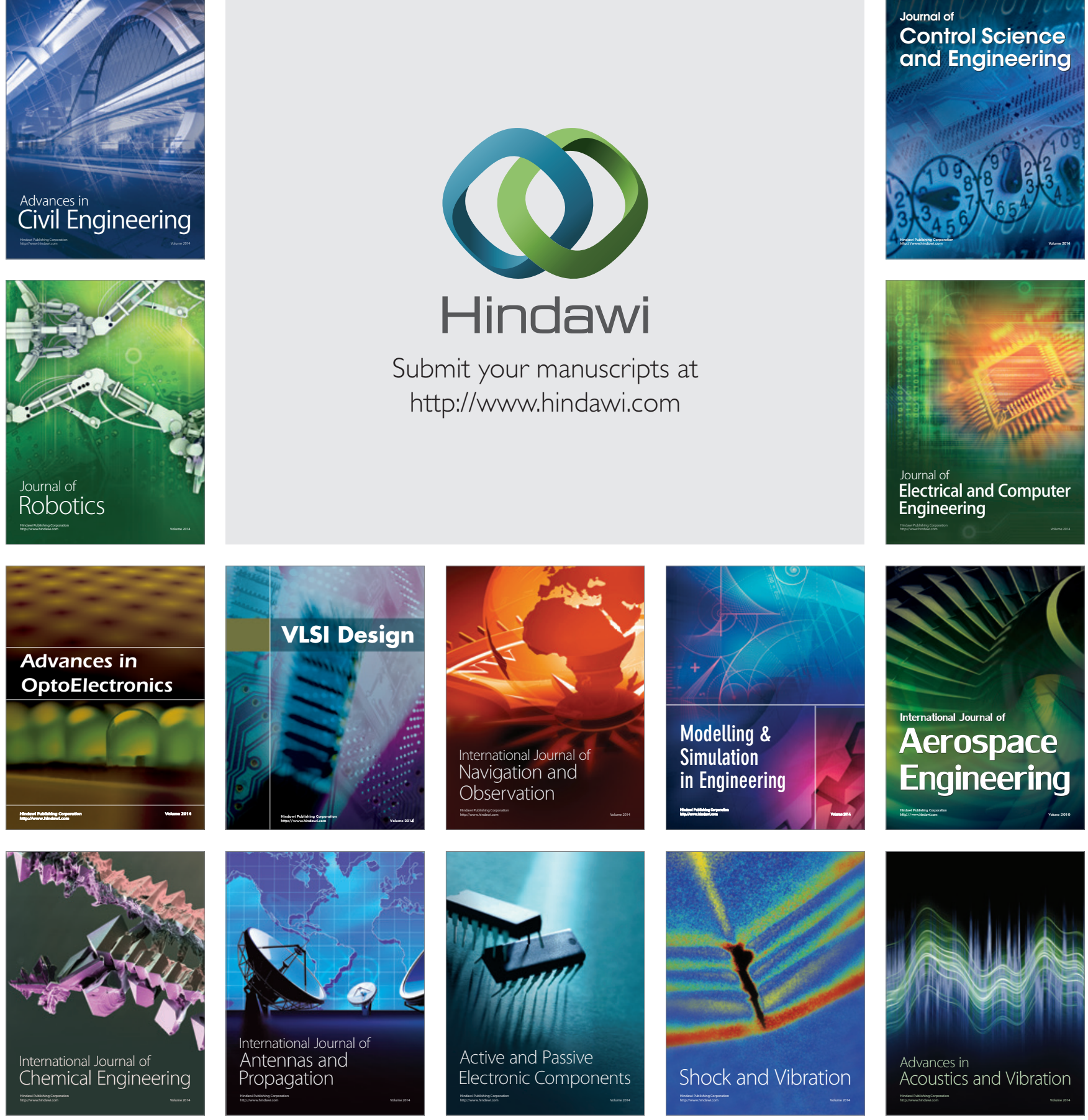